\title{
Communication \\ Photonic Crystals with an Eye Pattern Similar to Peacock Tail Feathers
}

\author{
Minghui Wang ${ }^{1,+}$, Fanshu Meng ${ }^{2,+}$, Hua $\mathrm{Wu}^{2}$ and Jingxia Wang ${ }^{2, *}$ \\ 1 College of Resources and Environment, Jilin Agricultural University, Changchun 130118, China; \\ wangluanluan88@163.com \\ 2 Key Laboratory of Bio-Inspired Smart Interface Sciences, Technical Institute of Physics and Chemistry, \\ Chinese Academy of Sciences, Beijing 100190, China; mfszjdm2014@gmail.com (F.M.); \\ wuhua632293437@163.com (H.W.) \\ * Correspondence: jingxiawang@mail.ipc.ac.cn; Tel.: +86-10-8254-3510 \\ + These authors contributed equally to this article. \\ Academic Editor: Qingfeng Yan \\ Received: 29 May 2016; Accepted: 16 August 2016; Published: 20 August 2016
}

\begin{abstract}
A facile fabrication of photonic crystals (PCs) with an eye pattern similar to peacock tail feathers has been demonstrated by self-assembly of colloidal particles in a sandwich mode. The sandwich mode is formed by superhydrophilic flat substrate sandwiching the poly(styrene-methyl methacrylate-arylic acid) (Poly(St-MMA-AA)) latex suspension ( $2 \mathrm{wt} \%)$ by the hydrophobic one. The patterns are characterized by optical microscopy images, reflection spectra, and the relative scanning electronic microscope images. This work will provide beneficial help for the understanding of the self-assembly process of colloidal crystals.
\end{abstract}

Keywords: photonic crystals; self-assembly; eyes pattern on peacock tail feathers

\section{Introduction}

Colloidal photonic crystals (PCs) have attracted great interest due to their special light manipulation properties [1,2], and have showed promising applications in various fields such as chemical and biological sensors [3,4], optic devices [5], coating materials [6], and catalytic supports [7]. Particularly, polymer colloidal PCs have demonstrated important applications ranging from photonic papers [8], full-color displays [9] and UV protection [10], to responsive optic devices. Various fabrication methods for colloidal PCs have been developed to meet practical application requirements [11-13]. Self-assembly is a facile approach for the fabrication of colloidal PCs with stopband at UV and visible ranges [14], and could be easily modified for widespread manufacturing purposes. A series of self-assembly methods have been established for the achievement of various unique functional materials. For example, crack-free colloidal PCs with narrow stopband were achieved on the low-adhesive/superhydrophobic substrate as the three phase contact line (TCL) reduced continuously $[15,16]$. Pattern colloidal PCs were manufactured from the printing technique by using the pattern substrate [17]. Functional 2-D high sensing films were produced from liquid surface, and magnetic Janus colloidal PCs were created from a microfluidic approach [18-20]. In the meantime, some novel assembly theory has been developed. In particular, the influence of the wettability on latex assembly is greatly understood in terms of the fabrication of specific functional PCs owing to its influence on the wetting, spreading, and evaporation time of the colloidal suspension. For example, superhydrophilic substrate was used for the continuous PCs [21], hydrophilic substrate was utilized for coffee-ring structure [22], while the pattern substrate with both hydrophobic or hydrophilic substrate was used for the pattern PCs [23]. In this paper, we present a facile fabrication of PCs with an eye pattern similar to peacock tail feathers by self-assembly of colloidal particles in a sandwich mode, 
with superhydrophilic flat substrate sandwiching of poly(styrene-methyl methacrylate-acrylic acid) (Poly(St-MMA-AA)) latex suspension by the hydrophobic one. The eye pattern is a concentric circle, with a green central circle and yellow circle brim. This may be aroused from different assembly structures of latex particles owing to the pinning TCL. The pattern is characterized by optical microscopy images, reflection spectra, and the relative scanning electronic microscope (SEM) images. A suitable concentration of Poly(St-MMA-AA) latex of $2 \mathrm{wt} \%$ is required for the production of a pattern structure. This work will provide an important insight for the self-assembly process.

\section{Results and Discussion}

The PCs with an eye pattern similar to peacock tail feathers was fabricated from the sandwich approach. That is, the Poly(St-MMA-AA) latex with concentration $2 \mathrm{wt} \%$ was sandwiched between the FAS silanized hydrophobic glass substrate and the superhydrophilic flat substrate treated by oxygen plasma. The samples were obtained after keeping the sandwich assembly system at $20^{\circ} \mathrm{C}$ for $12 \mathrm{~h}$. The colloidal particles are self-assembled and driven by the capillary force between the interface of the glass substrate and the convective force aroused from the solvent evaporation. Figure $1 \mathrm{a}, \mathrm{b}$ present the optical microscopy images of as-prepared samples. Figure 1a is a bright-field optical microscopy image of the front side of the samples that is exposed toward the air. Clearly, some crossed cracks are observed on the sample, a typical feature for the colloidal crystals from the assembly method. It is well known that the crack is formed by the compete effect of the shrinkage force of latex particles and resistance force of substrate toward the latex during the solvent evaporation process. Interestingly, an obvious eye pattern can be found on the back side of the samples as shown in Figure $1 b$, the side is cling to the superhydrophilic glass substrate (more images are in Figure S1). The eye pattern is similar to that of a peacock tail feather as shown in Figure 1d [24,25]. By further observing the eye pattern in Figure $1 \mathrm{~b}$ (bright-field optical microscopy image of the sample), it was found that the eye pattern is formed on the crack fraction of the sample. Furthermore, these eye pattern structures are grass-green in the middle of core, the structure color turns to yellow or orange around the green central part. Just like the eye pattern of peacock tail feathers, the color of the bulk PCs is grass-yellow color. In most cases, one eye pattern is formed for one fraction, while in very few cases, two eye patterns are seen in one fraction. The eye pattern can be found on many fractions, but it never crosses the cracks region as shown in Figure 1c.
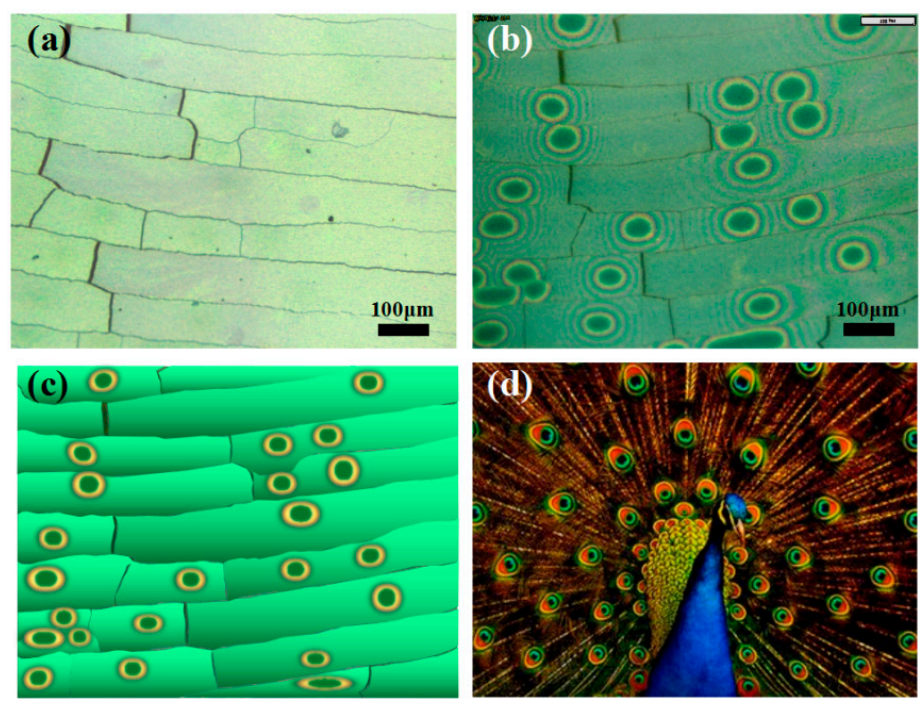

Figure 1. Optical microscope images of as-prepared sample. (a) Front side of the sample; (b) Back side of the sample; (c) Scheme for the as formed sample; (d) Eyes pattern of peacock tail feather (The picture was obtained from [25]). The front side of the sample shows crossed crack, while the back side of the sample shows plenty of the eyes pattern similar to the peacock tail feathers. 
Figure 2 showed the UV-vis reflection spectra of the eye pattern. It was generated by combining the optic fiber spectrometer with the optical microscopy. As expected, the distinct reflection spectra is captured for the sample at the different positions of the eye pattern. At the core part of the eye pattern, the reflection spectra of the sample is centered at $520 \mathrm{~nm}$ (as shown in 3 in the Figure 2b). Some red shift of the spectra is observed when the detecting position moved from the core to the exterior part of the eye pattern. Concretely, the centered position reflection spectrum changed to $525 \mathrm{~nm}$ (as shown in 2 in the Figure 2b). Finally, the sample demonstrated a reflection band centered at $556 \mathrm{~nm}$ (as shown in 1 in the Figure 2b) toward the whole PCs. That is, the eye pattern mainly originated from the different spectra position. It is known that coloration of peacock feather is mainly controlled by the lattice constant and the periodic number; varying the lattice constant and the number of periods brings about additional colors [24]. This implies that varying assembly structure should be captured for the different part of the eye pattern. Accordingly, we detected the assembly morphology of the sample by SEM images as shown in Figure 2c,d (more information is in supporting information Figures S3 and S4), it was found that a close-packed arrangement is taken for the green core region in Figure 2c, while the non-close packed, and more loose arrangement is observed for the circle brim (yellow or orange) region of the sample in Figure 2d. These different assembly structures correspond to the distinct spectra position in Figure $2 \mathrm{~b}$ based on the simulation calculation from Bragg-diffraction equation [26], a clear red-shift of spectra position arose from the non-close packed structure (brim region) comparing the close-packed structure (core part). This corresponds to the measured result in Figure $2 \mathrm{a}, \mathrm{b}$. The assembly structure change from close packed to non-close packed can be confirmed from cross-section SEM image in Figure 2e (relative images are in Figure S5). In short, three colors are observed for the formation of the eye pattern, one grass-green core region, the yellow or orange brim region, and the grass-yellow bulk region(relative reflection spectra is in Figure S6). Similar to the nature of peacock feather, the distinct color is originated from the lattice constant and the periodic number [24]. And we built schematic illustration for the general strategy to self-assembly of these samples in Scheme 1.
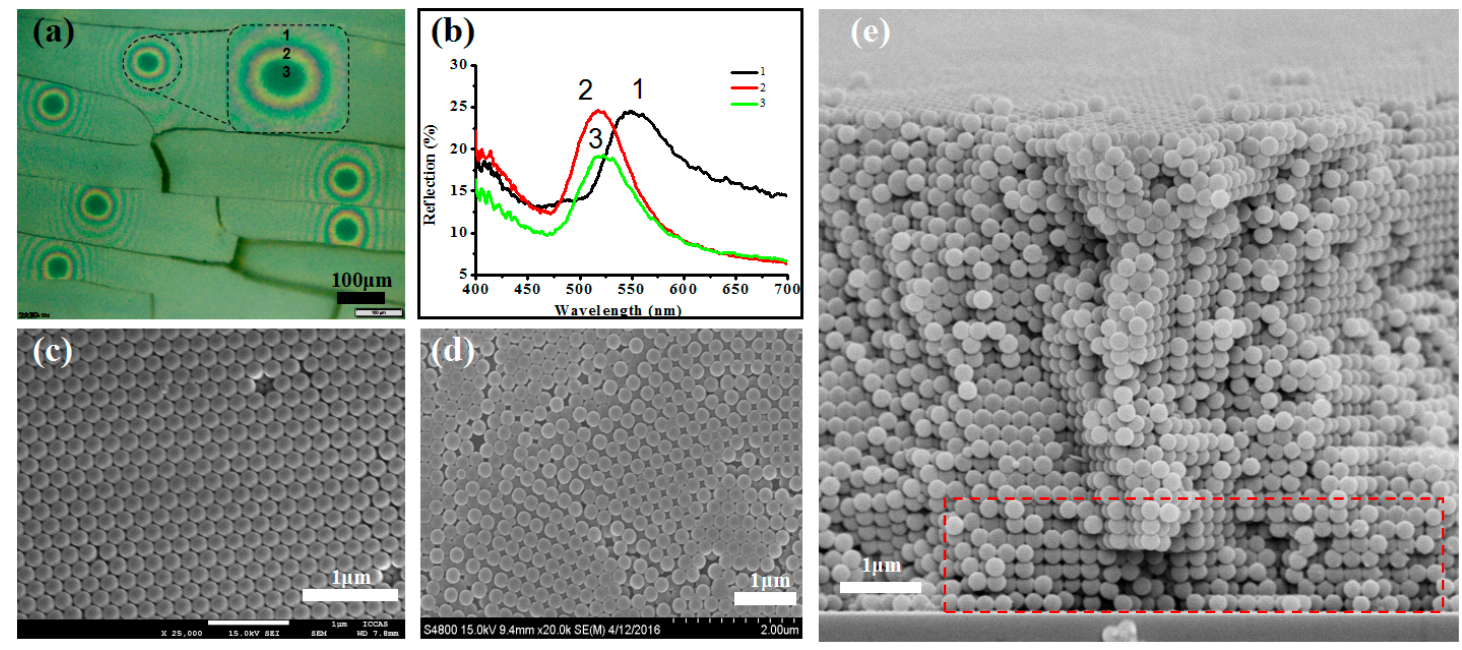

Figure 2. (a) Optical microscope image of the assembly sample with eye pattern; (b) UV-vis spectra of different parts of the peacock eye pattern structure; (c,d) SEM images of assembled photonic crystals (PCs) with close-packed arrangement (c) and non-closed packed region (d); (e) Cross section SEM image of sample in red rectangle part indicates the transverse of yellow and green connection part of the eye pattern. 
(a) Sandwich model
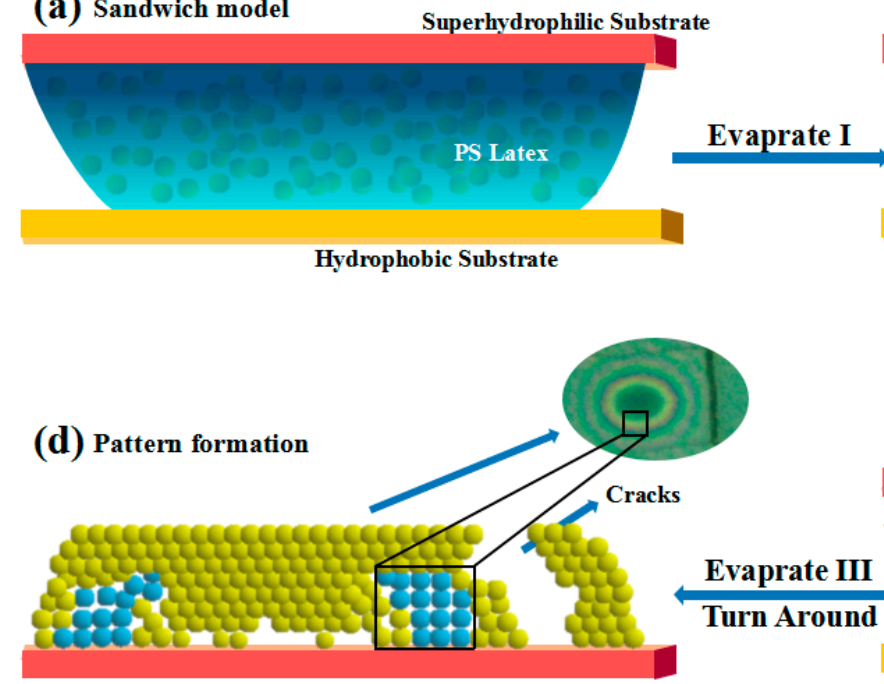

Eye pattern on peacock tail feathers (b) Self-assemly

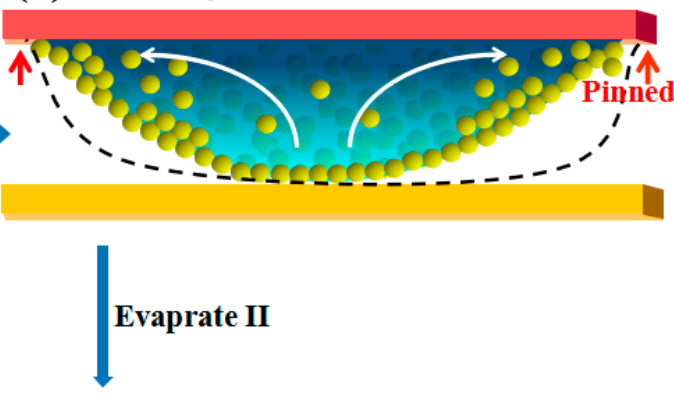

(c) Cracks and nonclose-packed regions formation

Scheme 1. Schematic illustration for the general strategy to self-assembly of PCs with eye pattern similar to the peacock tail feather. (a) Carefully dropping poly(styrene-methyl methacrylate-arylic acid) (Poly(St-MMA-AA)) latex onto the bottom glass and covered by the hydrophilic glass substrate, forming a sandwich assembly; (b) As solvent evaporating, latex assembly at the interface of gas-liquid; (c) The orderly arrangement (yellow particles) and disclose-packed regions (blue particles) assembled and forming cracks; (d) After removal of the bottom glass, the PCs with eye pattern of the peacock tail feathers can be generated. Black curves in (b) and (c) are receding three phase contact line (TCL).

To understand the influence of different assembly structures on spectra shift, we calculate the spectra position by Bragg diffraction equations as follows:

$$
\lambda_{\max }=2 d_{h k l}\left[n_{e f f}^{2}-\sin ^{2} \theta\right]^{1 / 2}
$$

$\lambda_{\max }$ is the wavelength of the diffraction peak, $d_{\mathrm{hkl}}$ is distance of between (h k l) plane, and can be assumed by Equation (2):

$$
d_{h k l}=\frac{a}{\sqrt{h^{2}+k^{2}}+l^{2}}
$$

a is lattice parameters (in FCC (close packed structure), $a=2 \sqrt{2} r$; in BCC (non-close packed structure), $a=4 r / \sqrt{3})$, in our experiment $\mathrm{r}=100 \mathrm{~nm}, d_{111}=163.3 \mathrm{~nm} d_{100}=231.0 \mathrm{~nm} ; \theta$ is the angle of incidence $\theta=90^{\circ}, \sin \theta=1$, and the Equation (1) can be simplified as $\lambda_{\max }=2 d_{h k l} n_{e f f}$. Parameter $n_{\text {eff }}$ is the effective refractive index of structures. Figure 2c shows ( 1111$)$ plane in face-centered cubic (FCC) structure, and Figure 2d shows ( $\left.\begin{array}{lll}1 & 0 & 0\end{array}\right)$ plane in body-centered cubic (BCC) structure. It is given by Equation (3):

$$
n_{\text {eff }}=\left(n_{\text {sphere }}^{2} f+n_{\text {air }}^{2}(1-f)\right)^{1 / 2}
$$

where $n_{\text {sphere }}$ and $n_{\text {air }}$ are refractive index of Poly(St-MMA-AA) sphere and air respectively $\left(n_{\text {sphere }}=1.5916\right.$ and $\left.n_{\text {sphere }}=1.0\right) ; f$ is the filling ratio of spheres (in FCC $f=0.74$ and in BCC $f=0.68$ ). $n_{\text {eff }}$ of FCC is 1.42920 and $n_{\text {eff }}$ of BCC is 1.461.

Through the calculation we can estimate the site of spectrum. The green part of FCC (111) should be at $477 \mathrm{~nm}$, and the yellow part of BCC $\left(\begin{array}{lll}1 & 0 & 0\end{array}\right)$ at $660 \mathrm{~nm}$. The calculation result proves that the red-shift of spectra can be aroused from close-packed to non-closed packed structure.

More investigation of eye pattern PCs is conducted by peeling the glass substrate off the sample as shown in Figures S2-S4. There are distinct adhesion forces between different regions of sample and substrate. A higher adhesion force is observed for the brim region of the eye-pattern, leading to plenty 
of remaining particles on the glass substrate (Figure S3e,f). In contrast, little particle can be found on the substrate for the core-part of the eye pattern (Figure S3e,f), indicating less adhesion force between the core part and substrate.

To clearly understand the formation process of PCs with eye pattern similar to the peacock tail feather, Scheme 1 puts forward a possible formation mechanism for the whole assembly process. At first, the Poly(St-MMA-AA) latex was sandwiched between the pre-treated hydrophobic and the superhydrophilic one. The latex suspension will spread fully onto the superhydrophilic substrate, keeping away from the hydrophobic one. During the evaporation process, TCL pins at the superhydrophilic substrate [27], but keeps continuously receding at the hydrophobic one. As TCL is pinned at the superhydrophilic substrate, hexagonal close-packed structures are obtained. However, as TCL receding continues with increased evaporation time, non-close-packed assembly structure can be formed [28] by the trace of the receding path. The change of the assembly structure from close-packed to non-close packed resulted in a red-shift of the optic signal as shown in Figure 2b. Generally, three assembly steps occur in the whole process based on distinct assembly concentration and evaporation time as shown in Scheme 1. The first assembly step takes place when TCL of the latex pins at the superhydrophilic substrate with the solvent evaporation, implying an initial assembly of latex particles at the interface of gas-liquid and solid-liquid in Scheme $1 \mathrm{~b}$. In this process, the close-packed assembly can be observed at the interface of the solid-liquid accompanied with the outward reflux of the latex owing to the fastest evaporation rate at the brim region. In the second assembly step, pinned TCL will recede owing to the increased assembly concentration accompanied with the evaporation time. Simultaneously, the non-close-packed assembly is observed at the solid-interface as shown in Scheme 1c resulting from the receding process of TCL $[28,29]$, corresponding to the red-shift at Figure $2 \mathrm{~b}$. The transformation from close packed to non-closed packed structure can be proved from cross-section SEM images in the red rectangle shown in Figure 2e. In the third assembly, TCL of the latex pinned again at the superhydrophilic substrate means that it was close-packed assembly again. However, owing to the outward transfer of the latex at the assembly I, less latex is left at the core part, resulting in a decreased periodic number of close-packed structure and blue-shift spectra signal than the bulk PC, which is consistent with the grass-green core of the eye-pattern. The presumption that less latex remained at the core part can be confirmed from the low adhesive property on core-part and high adhesion property on the brim part as shown in Figures S3 and S4. As a result, all of these contribute to the formation of an eye pattern similar to that of a peacock tail feather on the superhydrophilic substrate.

Table 1 summarizes the impact of different concentrations of Poly(St-MMA-AA) latex and different wettability of the top substrate on the as-formed PCs with or without eye pattern. It was found that suitable concentration is necessary for the formation of PCs with eye pattern. Higher latex concentration (i.e., $20 \mathrm{wt} \%$ ) will result in coffee-ring structure, while low latex concentration (i.e., $0.2 \mathrm{wt} \%$ ) will lead to discontinuous assembly. Only at the latex concentration of $2 \mathrm{wt} \%$ the film with eye pattern can be obtained. Otherwise, the wettability of the substrate plays an important role on the formation of eye pattern in the film. When the top substrate is superhydrophilic or hydrophilic, the PC with eye pattern can be obtained. In contrast, no eye pattern formed when the wettability of the top substrate is superhydrophobic. 
Table 1. The impact of different concentration of Poly (St-MMA-AA) latex and wettability of the top substrate.

\begin{tabular}{|c|c|c|}
\hline PS Concentration & Substrate Wettablity & \\
\hline $20 \%$ & superhydrophilic & \\
\hline $2 \%$ & hydrophilic & \\
\hline $0.2 \%$ & superhydrophobicity & No sample \\
\hline
\end{tabular}

\section{Materials and Methods}

Preparation of Poly(St-MMA-AA) latex. The monodispersed latex particles of Poly(St-MMA-AA) were chosen. We prepared it by modified emulusion polymerization with our previous method [30]. Aqueous solution of sodium dodecyl benzenesulfonate $(0-0.072 \mathrm{mM})$ and ammonium bicarbonate $(6.30 \mathrm{mM})$, and monomer mixture of methyl methacrylate (MMA, $10.00 \mathrm{mM})$, acrylic acid (AA, $13.89 \mathrm{mM})$, and styrene $(\mathrm{St}, 182.60 \mathrm{mM})$, were added into a four-necked flask. Subsequently, the above mixture was stirred at $70{ }^{\circ} \mathrm{C}$ for $10 \mathrm{~h}$ after charging the initiator of ammonium persulfate. The as-prepared latex particles can be used directly without purification. Through GPC, molecular weight of the sample found that the value of $\mathrm{Mn}=111,036, \mathrm{Mw}=299,265$, the polydispersity is 2.6952 . Otherwise, the free-radical emulsion polymerization with the three monomer was simultaneously added into the system, the as-prepared sample is a random polymer. The latex concentration can be varied by diluting the solution by deionized water.

Surface Modification for Different Glass Substrate. The hydrophobic treatment glass substrate was generated by silanizing it with heptadeca-fluorodecyltrimethoxysilane (FAS). Firstly, we put the substrate and FAS in a decompression environment at room temperature for $0.5 \mathrm{~h}$, and then kept the vacuum heated at $80{ }^{\circ} \mathrm{C}$ for $8 \mathrm{~h}$, which yielded our hydrophobic glass surfaces. Superhydrophilic glass substrates were obtained by oxygen plasma treatment. The relevant operating parameters are as follows: feed gas is oxygen; gas flow is 40 SCCM; backing vacuum degree (working pressure) is $40 \mathrm{~Pa}$; discharge power (working power) is $200 \mathrm{~W}$; working time is $10 \mathrm{~min}$. The water contact angle (CA) of the treated superhydrophilic substrate is $0^{\circ}$, and the obtained hydrophobic substrate is $130^{\circ}$.

Generation of Colloidal Pattern. A FAS treated hydrophobic glass substrate was first held horizontally. Then droped Poly(St-MMA-AA) latex with the colloidal suspension's weight concentration of $2 \%$ was put carefully onto the glass and covered with a plasma treated superhydrophilic glass substrate, forming a sandwich mode assembly. Keeping the assembly system at $20^{\circ} \mathrm{C}$ for $12 \mathrm{~h}$, the Poly(St-MMA-AA) microsphere assemblies containing eyes pattern of peacock tail feathers were obtained on the hydrophilic glass substrate.

Characterization. Bright-field optical microscopy images were taken by system microscopy (Olympus BX51, Osaka, Japan). The morphologies of aligned colloidal assemblies were investigated by SEM (JEOL, JSM-7500F, Tokyo, Japan) at an accelerating voltage of $5.0 \mathrm{kV}$. The oxygen plasma instrument (DT-03) is purchased from Suzhou OPS oxygen plasma Technology Co., Ltd (Suzhou, China). Static CAs were measured on a DataPhysics (Stuttgart, Germany) OCA20 contact-angle system 
at ambient temperature. UV-vis spectra were determined by combining the optic filber spectrum (NOVA, Idea Optics, Shanghai, China) and the optical microscopy.

\section{Conclusions}

In conclusion, we fabricated PCs with eye pattern similar to that of peacock tail feathers by sandwiching the Poly(St-MMA-AA) suspension between the superhydrophilic substrate and hydrophobic substrate. The eye pattern is a concentric circle, with a grass-green central circle and yellow or orange circle brim. This can be attributed to the distinct accumulation of micro-structure and the corresponding different reflection spectrum. This result will provide beneficial understanding for the self-assembly process of colloidal crystals.

Supplementary Materials: The following are available online at http://www.mdpi.com/2073-4352/6/8/99/s1, Figure S1: Optical microscope images of as-prepared sample, Figure S2: Scheme for the further investigation of the eye pattern PC, Figure S3: Optical microscope images and SEM images of as-prepared sample, Figure S4: SEM images of as-prepared eye-pattern sample after being peeling off the substrate, Figure S5: SEM images of cross-section of as-prepared sample, Figure S6: Reflection UV-vis spectra of different part of the peacock eye pattern structure.

Acknowledgments: Authors would like to thank the grant from MOST (No. 2016YFA0200803) and the NSFC (No. 51673207, 51373183).

Author Contributions: Jingxia Wang and Minghui Wang conceived and designed the experiments; Hua Wu and Fanshu Meng performed the experiments; Jingxia Wang and Minghui Wang analyzed the data; Fanshu Meng and Jingxia Wang wrote the paper.

Conflicts of Interest: The authors declare no conflict of interest.

\section{References}

1. Ge, J.P.; Yin, Y.D. Responsive photonic crystals. Angew. Chem. Int. Ed. Engl. 2011, 50, 1492-1522. [CrossRef] [PubMed]

2. Zhang, Z.M.; Geng, C.; Hao, Z.B.; Wei, T.B.; Yan, Q.F. Recent advancement on micro-/nano-spherical lens photolithography based on monolayer colloidal crystals. Adv. Colloid Interface Sci. 2016, 228, 105-122. [CrossRef] [PubMed]

3. Wang, F.Y.; Zhu, Z.G.; Xue, M.; Xue, F.; Wang, Q.H.; Meng, Z.H.; Lu, W.; Chen, W.; Qi, F.L.; Yan, Z.Q. Cellulose photonic crystal film sensor for alcohols. Sens. Actuators B Chem. 2015, 220, 222-226. [CrossRef]

4. Chen, T.; Deng, Z.Y.; Yin, S.N.; Chen, S.; Xu, C. The fabrication of 2D and 3D photonic crystal arrays towards high performance recognition of metal ions and biomolecules. J. Mater. Chem. C 2016, 4, 1398-1404. [CrossRef]

5. Li, Y.; Calvo, M.E.; Míguez, H. Integration of Photonic Crystals into Flexible Dye Solar Cells: A Route toward Bendable and Adaptable Optoelectronic Devices Displaying Structural Color and Enhanced Efficiency. Adv. Opt. Mater. 2016, 4, 464-471. [CrossRef]

6. Colson, P.; Cloots, R.; Henrist, C. Experimental design applied to spin coating of 2D colloidal crystal masks: A relevant method? Langmuir 2011, 27, 12800-12806. [CrossRef] [PubMed]

7. Li, P.; Wang, Y.; Chen, S.-L.; Wang, A.-J. Enhancement of gas-solid photocatalytic activity of nanocrystalline $\mathrm{TiO}_{2}$ by $\mathrm{SiO}_{2}$ opal photonic crystal. J. Mater. Sci. 2015, 51, 2079-2089. [CrossRef]

8. Fudouzi, H.; Xia, Y.N. Photonic papers and inks: Color writing with colorless materials. Adv. Mater. 2003, 15, 892-896. [CrossRef]

9. Yablonovitch, E. Inhibited Spontaneous Emission in Solid-State Physics and Electronics. Phys. Rev. Lett. 1987, 58, 2059-2062. [CrossRef] [PubMed]

10. Wang, J.X.; Liang, J.; Wu, H.M.; Yuan, W.F.; Wen, Y.Q.; Song, Y.L.; Jiang, L. A facile method of shielding from UV damage by polymer photonic crystals. Polym. Int. 2008, 57, 509-514. [CrossRef]

11. Zhang, L.J.; Xiong, Z.; Shan, L.; Zheng, L.; Wei, T.B.; Yan, Q.F. Layer-by-Layer Approach to (2+1)D Photonic Crystal Superlattice with Enhanced Crystalline Integrity. Small 2015, 11, 4910-4921. [CrossRef] [PubMed]

12. Ding, T.; Chen, L.; Long, Y.; Song, K. Micro-patterning of 3D colloidal photonic crystals via solvent-assisted imprint lithography. RSC Adv. 2015, 5, 8509-8513. [CrossRef] 
13. Cui, J.; Zhu, W.; Gao, N.; Li, J.; Yang, H.; Jiang, Y.; Seidel, P.; Ravoo, B.J.; Li, G. Inverse opal spheres based on polyionic liquids as functional microspheres with tunable optical properties and molecular recognition capabilities. Angew. Chem. Int. Ed. Engl. 2014, 53, 3844-3848. [CrossRef] [PubMed]

14. Yan, Q.F.; Zhou, Z.C.; Zhao, X.S. Inward-growing self-assembly of colloidal crystal films on horizontal substrates. Langmuir 2005, 21, 3158-3164. [CrossRef] [PubMed]

15. Griesebock, B.; Egen, M.; Zentel, R. Large Photonic Films by Crystallization on Fluid Substrates. Chem. Mater. 2002, 10, 4023. [CrossRef]

16. Huang, Y.; Zhou, J.M.; Su, B.; Shi, L.; Wang, J.X.; Chen, S.R.; Wang, L.B.; Zi, J.; Song, Y.L.; Jiang, L. Colloidal photonic crystals with narrow stopbands assembled from low-adhesive superhydrophobic substrates. J. Am. Chem. Soc. 2012, 134, 17053-17058. [CrossRef] [PubMed]

17. Wu, L.; Dong, Z.C.; Kuang, M.X.; Li, Y.N.; Li, F.Y.; Jiang, L.; Song, Y.L. Printing Patterned Fine 3D Structures by Manipulating the Three Phase Contact Line. Adv. Funct. Mater. 2015, 25, 2237-2242. [CrossRef]

18. Zhang, J.T.; Wang, L.; Lamont, D.N.; Velankar, S.S.; Asher, S.A. Fabrication of large-area two-dimensional colloidal crystals. Angew. Chem. Int. Ed. Engl. 2012, 51, 6117-6120. [CrossRef] [PubMed]

19. Zhang, J.T.; Chao, X.; Asher, S.A. Asymmetric free-standing 2-D photonic crystal films and their Janus particles. J. Am. Chem. Soc. 2013, 135, 11397-11401. [CrossRef] [PubMed]

20. Yin, S.N.; Yang, S.; Wang, C.F.; Chen, S. Magnetic-Directed Assembly from Janus Building Blocks to Multiplex Molecular-Analogue Photonic Crystal Structures. J. Am. Chem. Soc. 2016, 138, 566-573. [CrossRef] [PubMed]

21. Zhou, J.M.; Wang, J.X.; Huang, Y.; Liu, G.M.; Wang, L.B.; Chen, S.R.; Li, X.H.; Wang, D.J.; Song, Y.L.; Jiang, L. Large-area crack-free single-crystal photonic crystals via combined effects of polymerization-assisted assembly and flexible substrate. NPG Asia Mater. 2012, 4, e21. [CrossRef]

22. Yang, H.G.; Su, M.; Li, K.Y.; Jiang, L.; Song, Y.L.; Doi, M.; Wang, J.J. Preparation of patterned ultrathin polymer films. Langmuir 2014, 30, 9436-9441. [CrossRef] [PubMed]

23. Wang, Y.Z.; Wei, C.; Cong, H.L.; Yang, Q.; Wu, Y.C.; Su, B.; Zhao, Y.S.; Wang, J.X.; Jiang, L. Hybrid Top-Down/Bottom-Up Strategy Using Superwettability for the Fabrication of Patterned Colloidal Assembly. ACS Appl. Mater. Interfaces 2016, 8, 4985-4993. [CrossRef] [PubMed]

24. Zi, J.; Yu, X.D.; Li, Y.Z.; Hu, X.H.; Xu, C.; Wang, X.J.; Liu, X.H.; Fu, R.T. Coloration strategies in peacock feathers. Proc. Natl. Acad. Sci. USA 2003, 100, 12576-12578. [CrossRef] [PubMed]

25. Paw, Ogon, Kolory. Available online: http://www.tapeciarnia.pl/131841_paw_ogon_kolory (accessed on 14 July 2012).

26. Shi, L.; Harris, J.T.; Fenollosal, R.; Rodriguezl, I.; Lu, X.T.; Korgel, B.A.; Meseguerl, F. Monodisperse silicon nanocavities and photonic crystals with magnetic response in the optical region. Nat. Commun. 2013, 4, 1904. [CrossRef] [PubMed]

27. Cai, J.H.; Chen, S.R.; Cui, L.Y.; Chen, C.C.; Su, B.; Dong, X.; Chen, P.L.; Wang, J.X.; Wang, D.J.; Song, Y.L.; et al. Tailored Porphyrin Assembly at the Oil-aqueous Interface Based on the Receding of Three-phase Contact Line of Droplet Template. Adv. Mater. Interface 2015, 2, 1400365. [CrossRef]

28. Han, W.; Lin, Z.Q. Learning from "Coffee Rings": Ordered Structures Enabled by Controlled Evaporative Self-Assembly. Angew. Chem. Int. Ed. 2013, 51, 1534. [CrossRef] [PubMed]

29. Abkarian, M.; Nunes, J.; Stone, H.A. Colloidal Crystallization and Banding in a Cylindrical Geometry. J. Am. Chem. Soc. 2004, 126, 5978-5979. [CrossRef] [PubMed]

30. Wang, J.X.; Wen, Y.Q.; Ge, H.L.; Sun, Z.W.; Zheng, Y.M.; Song, Y.L.; Jiang, L. Simple Fabrication of Full Color Colloidal Crystal Films with Tough Mechanical Strength. Macromol. Chem. Phys. 2006, 207, 596-604. [CrossRef]

(C) 2016 by the authors; licensee MDPI, Basel, Switzerland. This article is an open access article distributed under the terms and conditions of the Creative Commons Attribution (CC-BY) license (http:/ / creativecommons.org/licenses/by/4.0/). 